\title{
TARGET EMMETROPIA IN MANUAL SMALL INCISION CATARACT SURGERY
}

K. Sathish, D. N. Prakash, B. K. Kanchana, Uma Balakrishnan, Ambika A. Acharya, Amar Kulkarni, Mohan Setlur, Jafar Sadik

1. Associate Professor. Department of Ophthalmology, Krishnarajendra Hospital, Mysore Medical College \& Research Institute, Mysore.

2. Assistant Professor. Department of Ophthalmology, Krishnarajendra Hospital, Mysore Medical College \& Research Institute, Mysore.

3. Resident. Department of Ophthalmology, Krishnarajendra Hospital, Mysore Medical College \& Research Institute, Mysore.

4. Resident. Department of Ophthalmology, Krishnarajendra Hospital, Mysore Medical College \& Research Institute, Mysore.

5. Resident. Department of Ophthalmology, Krishnarajendra Hospital, Mysore Medical College \& Research Institute, Mysore.

6. Resident. Department of Ophthalmology, Krishnarajendra Hospital, Mysore Medical College \& Research Institute, Mysore.

7. Resident. Department of Ophthalmology, Krishnarajendra Hospital, Mysore Medical College \& Research Institute, Mysore.

8. Resident. Department of Ophthalmology, Krishnarajendra Hospital, Mysore Medical College \& Research Institute, Mysore.

\section{CORRESPONDING AUTHOR:}

Dr. K. Sathish,

No. 826-I,'USHE',

9th B Cross Road, Roopa Nagar,

Mysore- 570026.

E-mail: drsathishkeshav@gmail.com

INTRODUCTION: Patient dissatisfaction is very common even with good cataract surgery. Cataract surgery done by phacoemulsification with foldable IOL implantation results in minimal astigmatism. This results in early rehabilitation thereby rendering the patient nearly emmetropic for both distant and near work. But the drawbacks of this surgical technique are high cost, steep learning curve and is entirely machine dependent.

This study has been conducted to know if it is possible to achieve minimal astigmatism with MSICS with rigid PMMA IOL in selected cases thus achieving cost effectiveness and reducing the duration of surgery.

AIMS AND OBJECTIVES: To study the visual outcome for both distant and near vision after manual small incision cataract surgery.

\section{MATERIALS AND METHODS:}

\section{INCLUSION CRITERIA:}

Visually significant cataracts -

PSC

NS grade II - III

Mature cataract

Hypermature cataract. 


\section{EXCLUSION CRITERIA:}

1. Cataract with retinal pathology like macular lesions, diabetic and vascular retinopathy etc.

2. Cataract with Pseudoexfoliation syndrome.

3. Cataract with advanced glaucomatous cupping

4. Subluxated / Dislocated cataract

5. Paediatric cataract

6. Traumatic cataract

7. Posterior polar cataract

8. Cataract with Rigid pupil.

The study was conducted between April 2009 and March 2011.A retrospective analysis of 1000 cases meeting the inclusion and exclusion criteria were selected.

All surgeries were performed by 2 experienced surgeons with emphasis on pre operative keratometry, A-scan biometry site, size and shape of incision, capsulorrhexis and inthe-bag placement of IOL; minimal handling of iris was ensured. Post operative vision, refraction was done at the end of $6 \mathrm{wks}$.

Frown shaped incision was planned and placed in the meridian of greatest corneal curvature based on keratometry readings. Capsulorrhexis, hydrodissection, prolapse and delivery of the nucleus was done using viscoexpression. Cortical wash with in the bag IOL placement done for all the cases.

\section{STATISTICAL ANALYSIS:}

- Visual acuity was converted into logMAR and decimal system for statistical calculations

- Univariate categorical analysis performed using chi-square test, two-paired t- test

- The level of statistical significance was set at $\mathrm{P}=0.05$ (two-sided)

\section{RESULTS:}

- A total of 1000 cases of MSICS were analyzed.

- Most of the patients were between 61yr to 70yrs of age (43.13\%).

- Females (58.2\%) were more than males (41.8\%).

- Posterior subcapsular cataract was the most common type of cataract $(42.2 \%)$.

- Uncorrected visual acuity of 6/18-6/9 at the end of $6 \mathrm{wks}$ was achieved by $900(90.0 \%)$.

- Near Vision of N8 - N10 was achieved by 437 (43.7\%).

- Post-operative AR readings ranging from +0.25 to - 1 D was achieved by 910 (91.0\%)

1. AGE: Ranged from 50 to 80 yrs

\begin{tabular}{|l|l|l|}
\hline AGE (in yrs) & No. of Patients & Percentage (\%) \\
\hline $51-60$ & 200 & 20.0 \\
\hline $61-70$ & 431 & 43.1 \\
\hline $71-80$ & 369 & 36.9 \\
\hline Test statistics & $\mathrm{X}^{2}=85.77 ; \mathrm{P}=.000(\mathrm{HS})$ \\
\hline
\end{tabular}




\section{ORIGINAL ARTICLE}

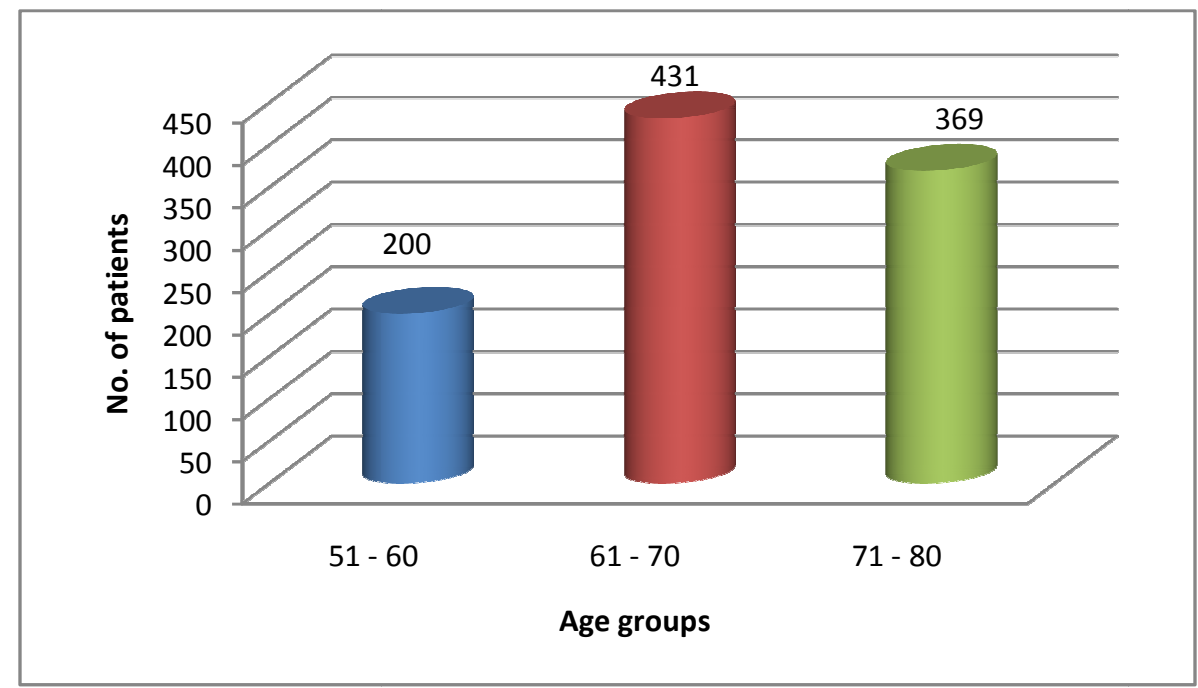

2. SEX:

\begin{tabular}{|l|l|l|}
\hline Female & 582 & $58.2 \%$ \\
\hline Male & 418 & $41.8 \%$ \\
\hline Test statistics & \multicolumn{2}{|l|}{$\mathrm{X}^{2}=26.896 ; \mathrm{P}=.000(\mathrm{HS})$} \\
\hline
\end{tabular}

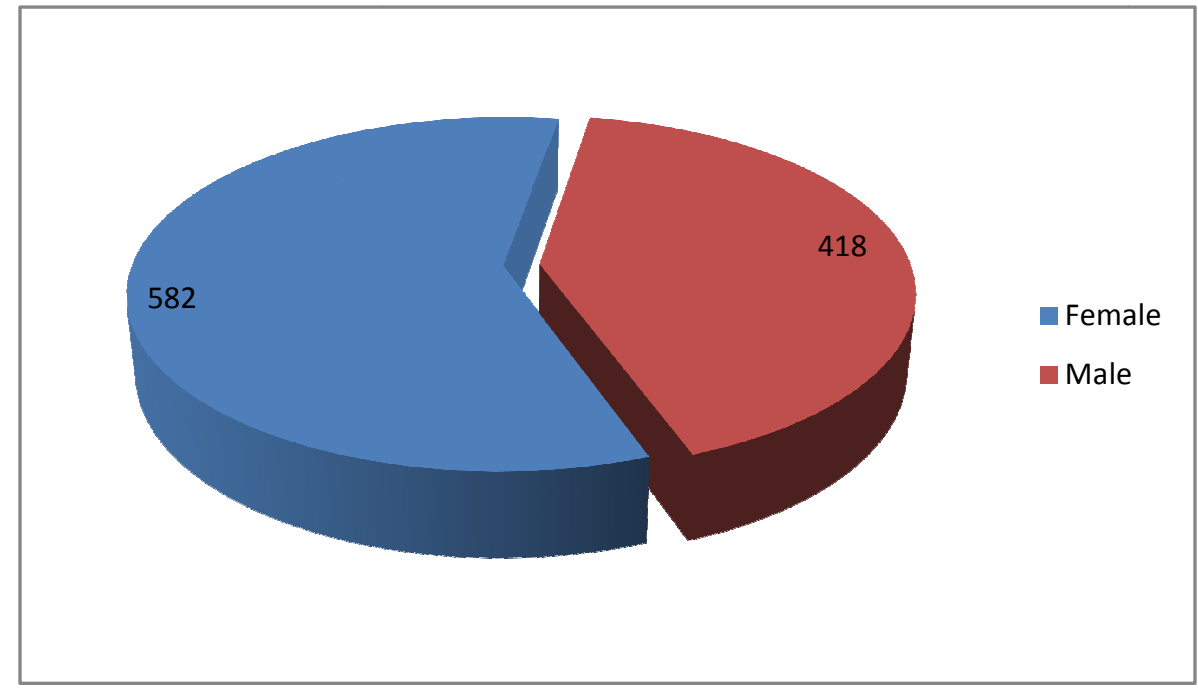

3. TYPE OF CATARACT:

\begin{tabular}{|l|l|l|}
\hline PSC & 422 & $42.2 \%$ \\
\hline Nuclear Cataract (grade II - IV) & 194 & $19.4 \%$ \\
\hline Mature Cataract & 254 & $25.4 \%$ \\
\hline Hypermature Cataract & 130 & $13.0 \%$ \\
\hline \multicolumn{2}{|c|}{ Test statistics } & $\mathrm{X}^{2}=188.544 ; \mathrm{P}=.000(\mathrm{HS})$ \\
\hline
\end{tabular}




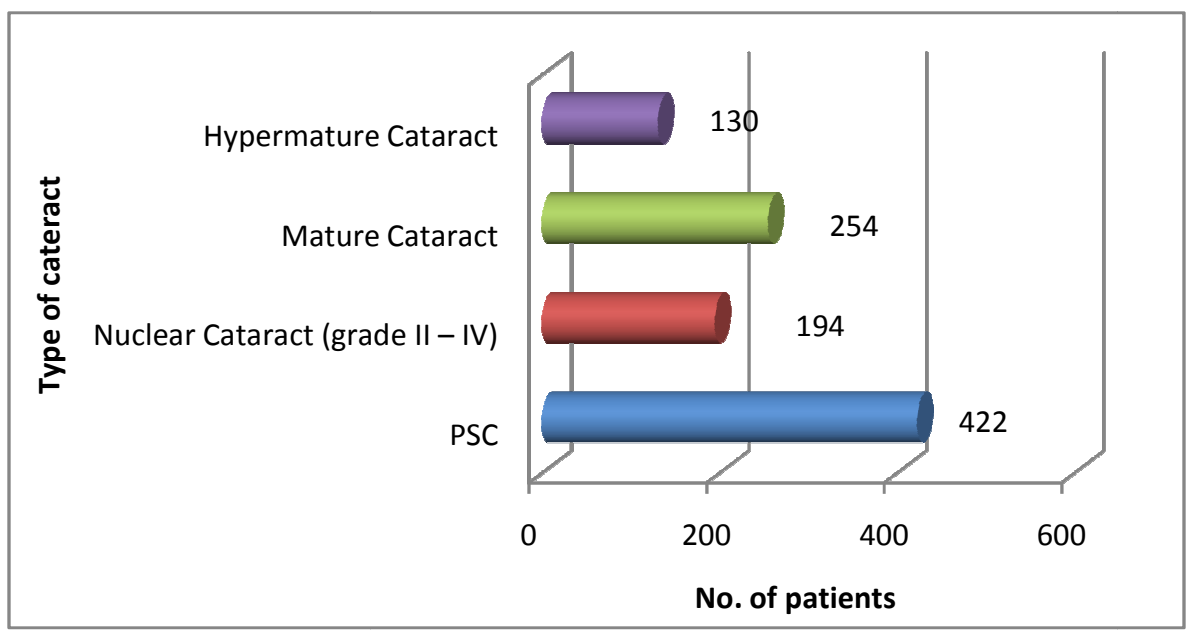

4. Uncorrected visual acuity at the end of 6wks:

Distant vision:

\begin{tabular}{|l|l|l|}
\hline DISTANT VISION & NUMBER & PERCENTAGE \\
\hline $6 / 18-6 / 9$ & 900 & $90.0 \%$ \\
\hline $6 / 24-6 / 18$ & 80 & $8 \%$ \\
\hline $6 / 60-6 / 24$ & 20 & $2 \%$ \\
\hline \multicolumn{1}{|c|}{ Test statistics } & $\mathrm{X}^{2}=1450.40 ; \mathrm{P}=.000(\mathrm{HS})$ \\
& \multicolumn{2}{|l}{} \\
\hline
\end{tabular}

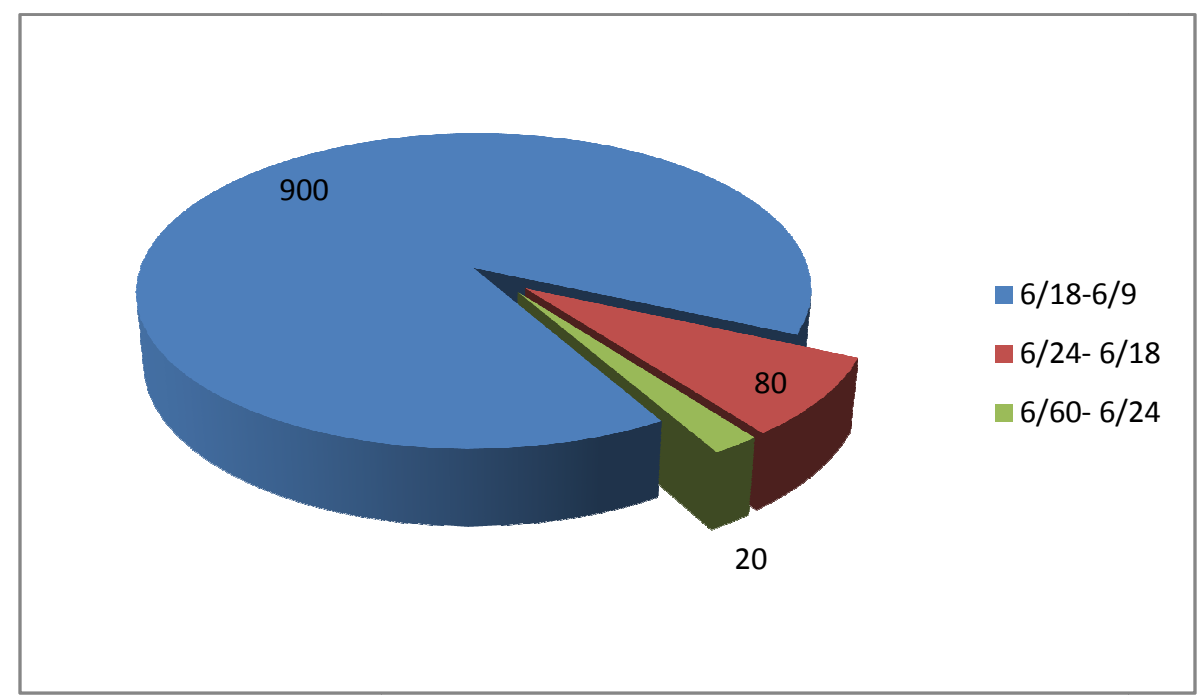

Near vision:

\begin{tabular}{|l|l|l|}
\hline Near Vision & Number of patients & Percentage \\
\hline N8 - N10 & 437 & $43.7 \%$ \\
\hline N10- N12 & 553 & $55.3 \%$ \\
\hline$<$ N12 & 10 & $1 \%$ \\
\hline \multicolumn{2}{|r|}{ Test statistics } & $\mathrm{X}^{2}=490.63 ; \mathrm{P}=.000(\mathrm{HS})$ \\
& \multicolumn{2}{|r|}{} \\
\hline
\end{tabular}




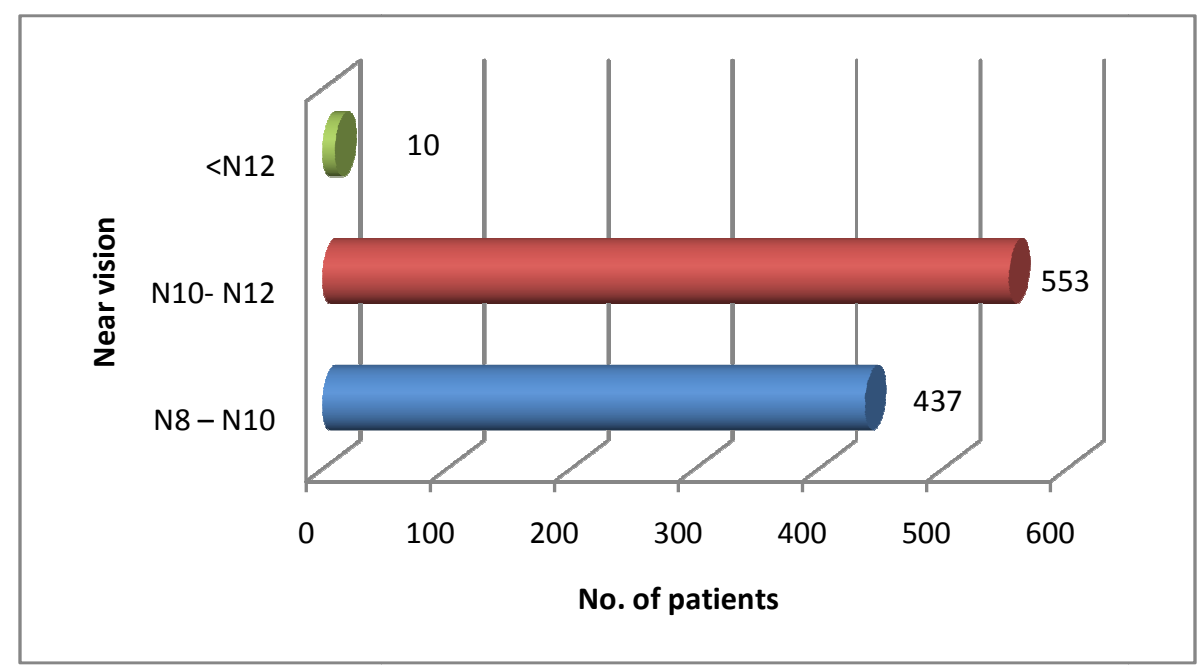

5. Best corrected visual acuity at the end of $6 \mathrm{wks}$ :

\begin{tabular}{|l|l|l|}
\hline DISTANT VISION & NUMBER & PERCENTAGE \\
\hline $6 / 18-6 / 9$ & 922 & $92.2 \%$ \\
\hline $6 / 24-6 / 18$ & 64 & $6.4 \%$ \\
\hline $6 / 60-6 / 24$ & 14 & $1.4 \%$ \\
\hline \multicolumn{2}{|c|}{ Test statistics } & $\mathrm{X}^{2}=1563.128 ; \mathrm{P}=.000$ (HS) \\
& \multicolumn{2}{|l}{} \\
\hline
\end{tabular}

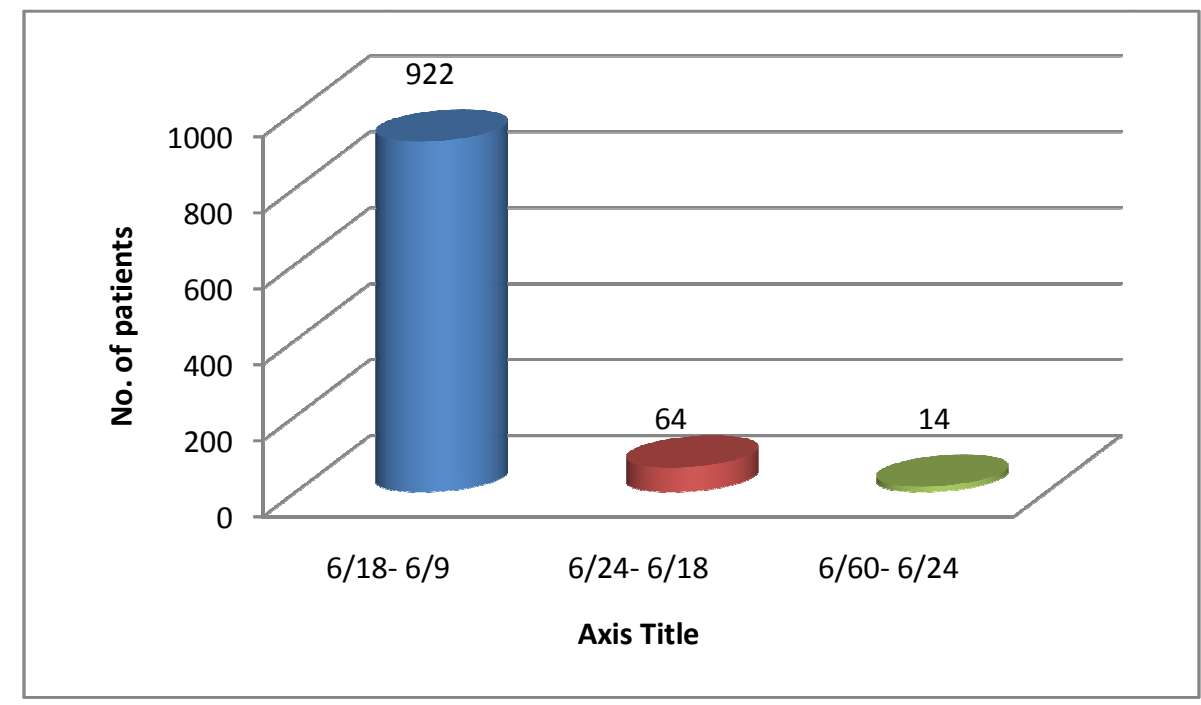

6. SURGICALLY INDUCED ASTIGMATISM:

\begin{tabular}{|l|l|l|}
\hline SIA & No. Of patients & Percentage \\
\hline $0-0.5 \mathrm{D}$ & 45 & $4.5 \%$ \\
\hline 0.5 to $1.0 \mathrm{D}$ & 298 & $29.8 \%$ \\
\hline 1.0 to $1.5 \mathrm{D}$ & 628 & $62.8 \%$ \\
\hline$>1.5 \mathrm{D}$ & 29 & $2.9 \%$ \\
\hline \multicolumn{2}{|r|}{ Test statistics } & $\mathrm{X}^{2}=944.22 ; \mathrm{P}=.000$ (HS) \\
& \multicolumn{2}{|l}{} \\
\hline
\end{tabular}




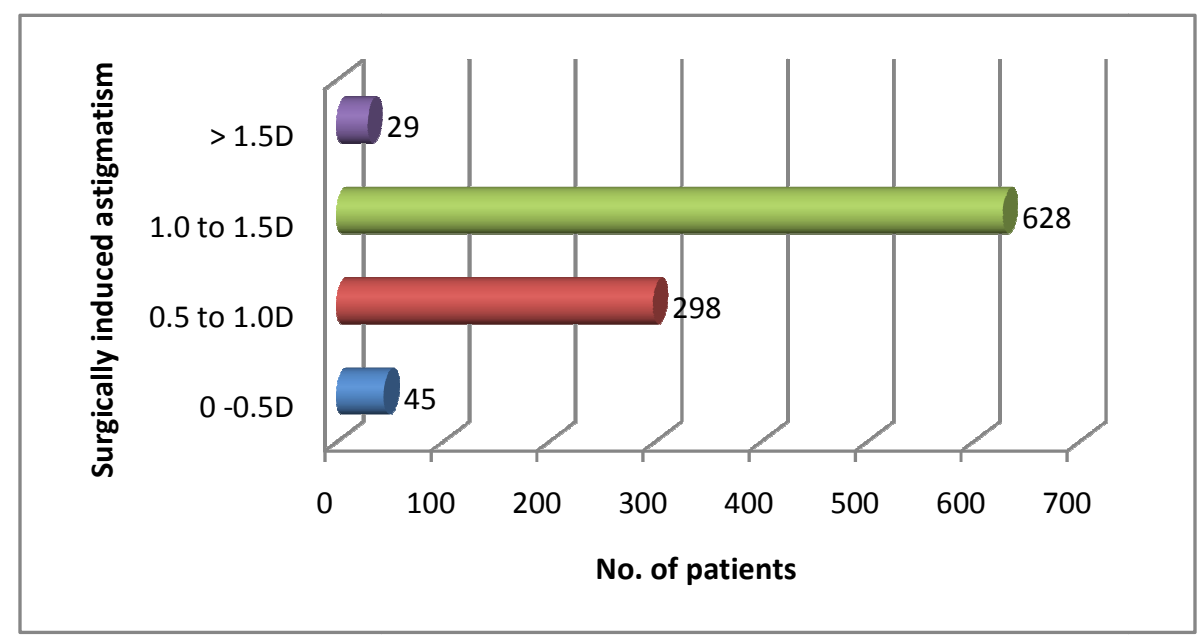

DISCUSSION : Achievement of this results in terms of visual acuity is greatly dependent on the 1.Astigmatism

2.The type of refractive error like a combination of ' + ' and '-' cylinder, thus Strum's conoid straddling the retina.

3. The near vision is greatly dependent on depth of focus and depth of field with a reactive pupil.

Depth of focus of an imaging system is defined to be the distance range (usually in millimeters) from the best-focused image distance where the resolution does not change or, equivalently, the blur caused by defocusing goes unnoticed

Depth of field, is defined as the distance range that an object may move (toward or away from a fixed-focus optical system) and still be considered in focus

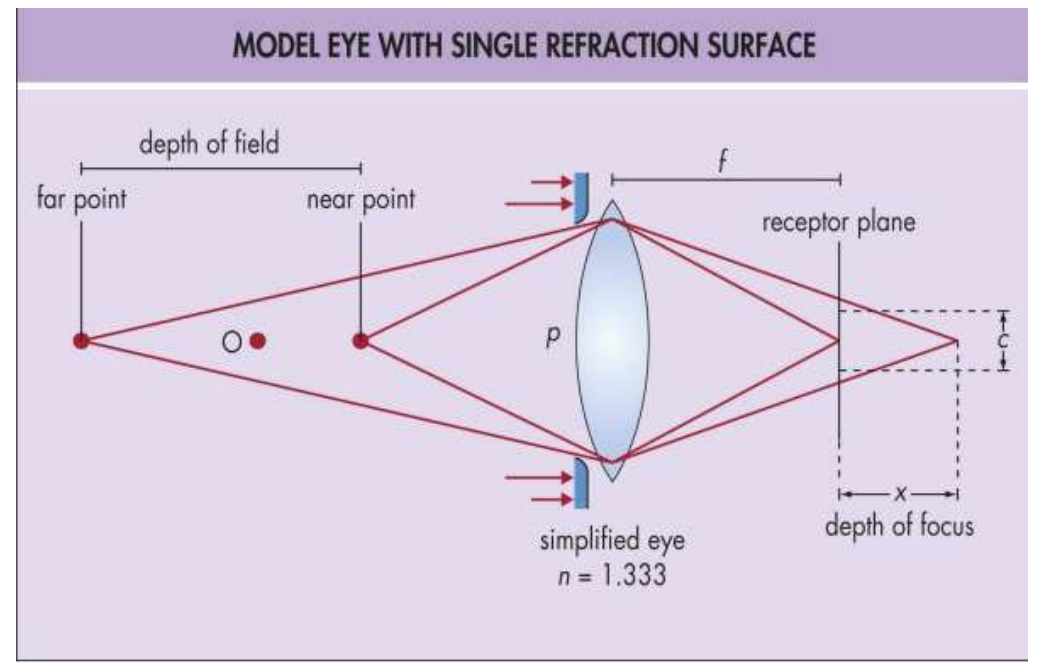


$\mathrm{O}=$ The object which can move from infinity to a near point

$\mathrm{p}=$ Pupillary diameter

$\mathrm{f}=$ Focal length of the model eye

$\mathrm{x}=$ Distance from the retina where the object at the near point comes to focus

$c=$ Photoreceptor size determining the eye's ultimate resolution

The depth of focus may be expressed by equation

$$
\mathrm{D}_{1}-\mathrm{D}_{2}=\frac{n}{f}-\frac{n}{f+x}=\frac{n x}{f(f+x)}
$$

$\mathrm{n}=$ Refractive index of the model eye

$D 1=n / f$, which is the dioptric power of the eye when an object is viewed at infinity

$D 2=n /(f+x)$, which is the dioptric power of the eye when an object is viewed at the near point

Behndig A et al conducted a study and concluded that emmetropia (spherical equivalent -0.5 to $+0.5 \mathrm{D}$ and $<1.0 \mathrm{D}$ astigmatism) is the goal in most cataract cases but was reached in only $55 \%$ of eyes planned for emmetropia. Factors precluding emmetropia included remaining corneal astigmatism and biometry prediction errors in astigmatic and ametropic eyes.

Zhou $\mathrm{Z}$ et al conduted a study and showed that of the 211 operated eyes, $73.2 \%$ were within +/$1.0 \mathrm{D}$ of the target refraction after surgery.

CONCLUSION : It is possible to achieve good visual outcome for both distant and near vision with minimal surgically induced astigmatism with MSICS with rigid PMMA IOL in selected cases, keeping in mind that depth of focus and depth of field is perfectly achieved

\section{REFERENCES:}

1. Behndig A, Montan P, Stenevi U, Kugelberg M, Zetterström C, Lundström M. Aiming for emmetropia after cataract surgery: Swedish National Cataract Register study. J Cataract Refract Surg. 2012 Jul;38(7):1181-6

2. Alpine NA, Incorporating refractive principles for better cataract surgery results, Special to ocular surgery News.

3. Stephenson M, Sharpen Your Skills to Target Emmetropia Achieving emmetropia after cataract surgery often comes down to surgeon technique and patient factors, Rev ophthalmol; March 2010

4. Shwartz GS.Intentionally Targeting Low Myopia After Cataract Surgery,Catarat Ref surg today, March 2008.

5. Refractive targeting in cataract surgery, Focus: Occasioanal update from the Royal College of ophthalmologists, 2003; 28.

6. Jaffe NS, Jaffe MS, Jaffe GF. Cataract surgery and its complications. 5th ed.CV Mosby; 1990. pp. 132-46.

7. Yanoff M, Duker JS, outcomes of cataract surgery: In Ophthalmology,3rd ed.Mosby, 2008.

8. Schechter RJ , Optics of Intraocular lenses; In Duane's Clinical Ophthalmology, Lippincott Williams \& Wilkins, 2005.

9. Finkelman YM, Ng J, Barrett G, Patient satisfaction and visual function after pseudophakic Monovision, Journal of cataract and refractive surgery (impact factor: 2.75). 07/2009; 35(6):998-1002. 